
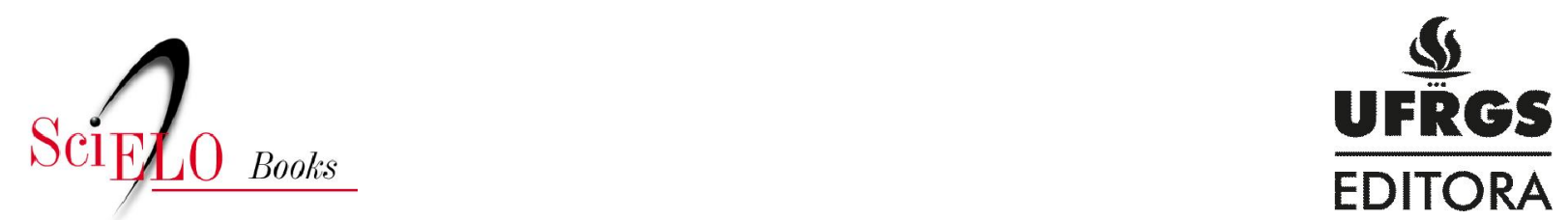

\title{
10 - Independência, marginalização e reafirmação da África (1957-2007)
}

\author{
Paulo Gilberto Fagundes Visentini
}

\section{SciELO Books / SciELO Livros / SciELO Libros}

VISENTINI, PGF. Independência, marginalização e reafirmação da África (1957-2007). In:

MACEDO, JR., org. Desvendando a história da África [online]. Porto Alegre: Editora da UFRGS, 2008. Diversidades series, pp. 123-137. ISBN 978-85-386-0383-2. Available from: doi:

10.7476/9788538603832. Also available in ePUB from:

http://books.scielo.org/id/yf4cf/epub/macedo-9788538603832.epub.

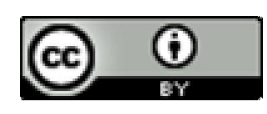

All the contents of this work, except where otherwise noted, is licensed under a Creative Commons Attribution 4.0 International license.

Todo o conteúdo deste trabalho, exceto quando houver ressalva, é publicado sob a licença Creative Commons Atribição $\underline{4.0}$.

Todo el contenido de esta obra, excepto donde se indique lo contrario, está bajo licencia de la licencia $\underline{\text { Creative Commons }}$ $\underline{\text { Reconocimento 4.0. }}$. 


\section{INDEPENDÊNCIA, MARGINALIZAÇÃO \\ E REAFIRMAÇÃO DA ÁFRICA \\ (1957-2007)}

\section{Paulo Gilberto Fagundes Visentini}

A descolonização da África negra foi tardia e relativamente controlada, pois as potências coloniais se anteciparam à radicalização dos protestos e puderam encaminhar as independências. Estudantes oriundos das elites locais foram enviados para estudos superiores nas metrópoles, a administração tornava-se paulatinamente africanizada e assessorada por técnicos europeus, enquanto a autonomia política era concedida progressivamente a uma burguesia nativa previamente cooptada.

Os primeiros países africanos a se libertarem, entretanto, foram os que mais lutaram para escapar do neocolonialismo. Em 1957, Gana independizou-se da Inglaterra, e o Primeiro-Ministro Nkrumah adotou uma política de neutralismo ativo, aproximou-se da URSS e da China Popular e declarou-se partidário do Pan-africanismo. No ano seguinte, a Guiné separou-se da França, e o Primeiro-Ministro Sekou Touré recebeu apoio dos países socialistas por sua linha política próxima à de Nkrumah.

Em 1960, o "ano africano", a maioria dos países do continente tornou-se independente da França e da Grã-Bretanha, dentro da linha "pacífica", gradual e controlada: Camarões, Congo-Brazzaville, Gabão, Chade, República Centro-africana, Togo, Costa do Marfim, Daomé (atual Benin), Alto Volta (atual Burkina Fasso), Níger, Nigéria, Senegal, Mali, Madagascar, Somália, Mauritânia e Congo-Leopoldville (atual Zaire). Entre 1961 e 1966 foi a vez de Serra Leoa, Tanzânia, Uganda, Ruanda, Burundi, Quênia, Gâmbia, Botswana e Lesoto. Todos os novos Estados localizavam-se na zona tropical africana 
e, neles, era limitado o número de colonos europeus, o que facilitou a transferência do controle formal dos diversos países à burguesia e classe média negra.

Nem tudo, entretanto, correu tão tranqüilamente. No CongoLeopoldville, os belgas abandonaram precipitadamente o país assim que eclodiram os primeiros distúrbios. Patrice Lumumba, líder nacionalista e progressista congolês, foi assassinado durante a guerra civil por Mobutu, que implantou um regime neocolonial.

Vários Estados africanos, face à sua debilidade, tentaram associarse em nível continental, dentro dos postulados pan-africanistas, ou federar-se pragmaticamente em escala regional, mas a falta de mínimas condições objetivas impediu a realização dessas aspirações. Apesar das divergências existentes na Conferência de Addis Abeba, em 1963, foi criada a Organização da Unidade Africana (OUA), com comissões para arbitramento de conflitos e comitês de libertação para os territórios ainda submetidos. A OUA aprovou como regra para a África a manutenção das fronteiras herdadas do colonialismo, diante da absoluta falta de outros parâmetros para delimitação dos novos Estados.

A maioria dos países francófonos manteve alguns vínculos com a ex-metrópole através da Comunidade Francesa de Nações, e os anglófonos com a Commonwealth britânica. Além disso, quase todos os demais assinavam acordos bilaterais com a antiga potência colonial ou com os EUA, abarcando várias áreas de cooperação. No campo militar, efetivavam-se, através da venda de armas, treinamento de oficiais e presença de assessores e missões. No plano cultural, o intercâmbio fazia com que até as cartilhas de alfabetização viessem da Europa, onde também estudavam os jovens da elite, futuros administradores do país.

Quanto à economia, não só a dependência externa enquanto países exportadores de matérias-primas e produtos primários implicava a manutenção de vínculos de subordinação, agora modernizados, como no plano interno permaneciam quase inalterados os sistemas de produção e preservavam-se os interesses estrangeiros. A ca- 
rência tecnológica e a falta de técnicos tornavam esta subordinação estrutural. No tocante à diplomacia, a maioria das jovens nações africanas tinha pouca margem de manobra, devido à falta de recursos e à dependência externa. Esses fatores serviam para configurar uma relação tipicamente neocolonial.

Os problemas africanos eram imensos. As fronteiras desses países eram artificiais, tanto no que se refere ao mínimo critério de racionalidade geoeconômica como histórico-cultural. Grupos etno-lingüísticos rivais eram reunidos em um mesmo Estado, enquanto outros afins encontravam-se separados por uma linha traçada à régua no mapa. O Estado antecedia à existência de uma nação. $\mathrm{Na}$ ausência de um idioma comum, oficializava-se o do ex-colonizador, enquanto a massa camponesa analfabeta continuava a utilizar os diversos dialetos tribais. As rivalidades entre os distintos grupos haviam sido estimuladas pelos colonizadores como forma de dominação, e deixavam uma herança trágica, expressa no problema das minorias e do "tribalismo", além do antagonismo entre assimilados à cultura européia e não-assimilados. A ausência de médicos, engenheiros, administradores e professores somava-se a uma estrutura de classes fragmentada, nos marcos de uma economia controlada de fora (exceto as extensas áreas ainda na fase da subsistência). A precaríssima rede de transportes ligava apenas os enclaves exportadores aos portos, inexistindo qualquer integração nacional.

Contudo, muitos dos constantes golpes de Estado, perpetrados pelo exército, possuíam um caráter progressista e modernizador, pois a instituição era uma das poucas de expressão nacional, acima das divisões tribais e em contato com a realidade social do país - embora a maioria deles não conseguisse implementar seu programa. Da mesma forma, a quase duplicação do número de Estados existentes em apenas uma década, apesar da fragilidade dos mesmos, não deixou de alterar profundamente as relações internacionais, transformando o caráter da ONU e reforçando o Movimento dos Não-Alinhados. 


\section{As Independências Revolucionárias \\ e a Guerra Fria}

A descolonização da África no início dos anos 1960 deixou de fora os chamados "bastiões brancos" do sul do continente. Portugal, que servia de "testa de ferro" aos interesses econômicos transnacionais, recusou-se a independizar Angola e Moçambique. A África do Sul, governada pela minoria branca ( $20 \%$ da população), controlava a Namíbia e na Rodésia (atual Zimbábue), os colonos brancos (5\% da população) apoiaram Ian Smith na proclamação da independência em 1965, a qual não foi reconhecida por Londres. A África do Sul, onde a segregação racial do Apartheid estava consagrada na Constituição, possuía grande força econômica e estava associada aos capitais estrangeiros e às empresas transnacionais. A África Austral, em seu conjunto, possuía imensas reservas de minerais estratégicos e potencialidades agrícolas, além de deter uma posição geopolítica estratégica na rota entre o Oceano Atlântico e Índico.

$\mathrm{Na}$ África Portuguesa, após quinze anos, a luta armada também seria coroada por uma vitória. Em Moçambique, a guerrilha implantara-se no norte, na fronteira com a Tanzânia. A Frente de Libertação de Moçambique (FRELIMO), dirigida por Samora Machel, já controlava parte do país, quando a Revolução dos Cravos em Portugal (1974) precipitou os acontecimentos. Moçambique passou a ser governado por um movimento predominantemente negro, que se proclamava marxista-leninista, junto às fronteiras da Rodésia e da África do Sul, países ainda controlados por minorias coloniais, onde intensificava-se a luta armada. Em 1976, ocorria o Levante de Soweto, duramente reprimido pelo Apartheid. As pequenas colônias portuguesas da Guiné-Bissau, de Cabo Verde e São Tomé e Príncipe também independizaram-se com governos populares.

A independência de maior impacto, entretanto, foi a de Angola, com maiores potencialidades econômicas e com expressiva minoria branca - o país dispõe de petróleo, ferro, diamantes, entre outros 
minerais estratégicos. A divisão e o confronto entre os três grupos que lutavam pela independência acirraram-se ainda mais quando da derrocada do fascismo português. A Frente Nacional de Libertação de Angola (vinculada aos EUA) e as tropas do Zaire avançaram do norte para atacar a capital, Luanda, onde o Movimento Popular para a Libertação de Angola (MPLA) era dominante. A invasão foi derrotada pelo MPLA com apoio de instrutores cubanos, que começavam a chegar ao país. Entretanto, no sul os grupos da União para a Independência Total de Angola (UNITA) e o exército sul-africano desencadearam uma guerra-relâmpago contra o MPLA de Agostinho Neto.

Face à situação desesperadora, iniciou-se uma ponte aérea entre Havana e Luanda, com o envio de armas e vinte mil soldados. No centro do país, as tropas cubanas (a maioria descendente de ex-escravos) e do MPLA derrotaram o exército sul-africano, um dos melhores do mundo. Assim, o MPLA governaria sozinho o país, havia declarado uma República Popular de inspiração marxista-leninista, mas enfrentava a guerrilha étnica da UNITA no sul, liderada por Jonas Savimbi (ligado a Pretória e Washington). A África do Sul ocupou uma faixa do sul de Angola para manter viva a UNITA, desestabilizar o governo do MPLA e impedir a infiltração dos guerrilheiros da Organização Popular do Sudoeste Africano - SWAPO (apoiados por Luanda) na Namíbia. Os cubanos permaneciam um pouco ao norte dos sul-africanos para impedir a invasão ao centro do país. A situação dos novos Estados era difícil, pois a maioria dos colonos retirara-se, privando-os de capitais, técnicos e administradores, enquanto tinham de enfrentar o caos interno e as invasões externas.

Na Etiópia, castigada pela miséria, seca e pelas guerrilhas muçulmanas e esquerdistas na Eritréia, o velho imperador pró-americano Haile Selaissie foi derrubado em 1974 por um golpe militar com apoio popular. A junta militar (DERG) exprimia um populismo pouco definido, enquanto as oposições, o caos e as tendências centrífugas ameaçavam a existência do novo regime. Este, enquanto crescia a luta de facções dentro do grupo dirigente, ligava-se cada vez mais às corren- 
tes de esquerda e implementava uma ampla reforma agrária, mobilizava a população, rompia com os EUA e enfrentava os movimentos de oposição. Em 1977, ascendeu à direção do DERG o coronel Mengistu Haile Marian (formado nos EUA). Enquanto definia-se pelo socialismo, as rebeliões separatistas ou autonomistas agitavam quase todas as províncias, e a Somália, país que, apesar de proclamar-se socialista e ser aliado da URSS, atacou a Etiópia, da qual Moscou acercava-se.

$\mathrm{Na}$ África Austral, a mobilização negra e os atentados do CNA intensificavam-se, apesar da crescente repressão e militarização do Estado sul-africano. Entretanto, o grande evento na região foi a ascensão ao poder da ZANU (União Nacional Africana do Zimbábue) na Rodésia, através de eleições patrocinadas pela Grã-Bretanha. Sem condições de derrotar a guerrilha negra, a minoria branca apelou para a mediação da ex-metrópole. O novo presidente, o marxista Robert Mugabe, formou um governo de coalizão com a ZAPU (União do Povo Africano do Zimbábue) e teve a habilidade de oferecer garantias aos brancos e a suas empresas, os quais permaneceram no país, mantendo sua prosperidade e permitindo o encaminhamento de reformas favoráveis à maioria negra. $\mathrm{O}$ país voltou à denominação africana de Zimbábue. Essa original revolução africana deixou a África do Sul isolada na região, embora esse país castigasse os vizinhos com freqüentes ataques de comandos e bombardeios.

\section{A Marginalização da África}

Na segunda metade dos anos 1980, as conseqüências dos conflitos africanos, da Nova Guerra Fria e da reestruturação da economia mundial continuavam a agravar-se. A União Soviética e os regimes revolucionários do continente, seus aliados, encontravam-se numa posição cada vez mais difícil. Assim, quando Gorbachov chegou ao poder em 1985, procurou buscar um entendimento com os EUA. Em troca da redução da corrida armamentista, a URSS passou, 
em fins de 1987, a pressionar seus aliados regionais a buscar uma acomodação política. Já na África do Sul, a situação foi mais complexa. Em 1988, as tropas cubano-angolanas derrotaram de forma esmagadora forças regulares sul-africanas e da UNITA em Cuito-Cuinavale no sul de Angola, e a aviação cubana atacou a represa que fornecia energia ao norte da Namíbia. Ficava patente para a própria África do Sul, extremamente desgastada pela guerra, que era hora de negociar. Os americanos propunham o princípio do Linkage: a retirada cubana em troca da independência da Namíbia, que Pretória acabou aceitando, ainda que procurando ganhar tempo.

Em 1989, os cubanos retiraram-se de Angola (e do resto da África), no mesmo ano em que o muro de Berlim era aberto, iniciandose o difícil processo eleitoral na Namíbia, sob os auspícios da ONU. Depois de se estabelecerem prerrogativas especiais para a minoria branca e para o capital internacional, ocorreram eleições que foram vencidas pela SWAPO. Em março de 1990, a Namíbia tornou-se independente. Ao mesmo tempo, os ventos democratizantes, associados ao reordenamento mundial, varriam a África. Regimes de partido único eram substituídos, frente às pressões internas e externas, por sistemas liberal-democráticos multipartidários. Estados em guerra civil como Angola (maio de 1991) e Moçambique (outubro de 1992) assinavam acordos de Paz, e os demais regimes marxistas eram derrubados, como na Etiópia em maio de 1991. A própria África do Sul anunciou, em fevereiro do mesmo ano, o fim do Apartheid, após a libertação do líder negro Nelson Mandela no ano anterior.

A adequação da África aos parâmetros da chamada Nova Ordem Mundial, contudo, não significava a solução dos problemas existentes. O fim da bipolaridade e do próprio conflito Leste-Oeste, agravado pelo desmembramento e desaparecimento da União Soviética em fins de 1991, fez com que o continente africano perdesse sua importância estratégica e capacidade de barganha, ao que se acrescentava a própria perda de importância econômica. A Guerra do Golfo, por sua vez, reforçara esta tendência. O resultado foram a marginalização da África no 
sistema internacional e a desestrategização e tribalização dos conflitos e da política regional. Com armas menos modernas, financiamento das máfias e senhores da droga (cujo cultivo se expandia rapidamente em muitas regiões do continente), e intromissão de potências médias locais e externas, esses conflitos persistiram, até como forma de sobrevivência das elites e das populações nas áreas mais afetadas. Alguns acordos de paz, como os de Angola, não foram respeitados, com a persistência da guerra e a devastação de amplas regiões.

A instabilidade no continente também afetou os Estados do Golfo da Guiné. O mais importante país da região, a Nigéria, viveu, ao longo dos anos 1990, uma turbulência política interna permanente, com a oscilação entre avanços eleitorais da oposição e novos golpes militares. Além disso, as guerras civis alastraram-se pela região: Senegal (região de Casamance), Libéria, Serra Leoa e a longa guerra dos Estados do Sahel (Mali, Níger, Mauritânia e a própria Argélia) contra os nômades tuaregues do deserto. Embora a OUA tenha criado forças de paz para barrar os conflitos da Libéria e Serra Leoa, ainda não conseguiu debelar esses conflitos. Nestes, a fratura principal ocorre entre os nativos do interior e os descendentes ocidentalizados de ex-escravos das Américas, que retornaram à África no século XIX, e habitam o litoral. Acrescente-se a isso que, após uma breve redemocratização, muitos regimes autoritários estão voltando ao poder na África, ou pelo menos antigos ditadores vencem eleições ou reassumem na esteira de conflitos internos, geralmente com apoio popular.

Apesar desses problemas, existem alguns processos positivos que sinalizam a reafirmação da África na cena internacional. É o caso da África Austral, outra região considerada importante no contexto da globalização, devido a suas reservas minerais e sua relevante posição geopolítica. Tanto aqui como no Oriente Médio, os conflitos regionais conduziam à radicalização social, à instabilidade diplomática e aos excessivos gastos em defesa e segurança, os quais foram consumindo as riquezas locais, obrigando o Ocidente a auxiliá-las economicamente. O Apartheid começou a ser desativado pelo presidente Frederik De Klerk, 
em um tortuoso processo que culminou com a eleição de Nelson Mandela à presidência do país em 1994. Esse caminho foi difícil, com inúmeros conflitos internos, o que também veio a ocorrer com os processos de paz em Angola e Moçambique, este último pacificado em 1992, enquanto o primeiro só teve a guerra encerrada uma década depois, quando o isolado Jonas Savimbi veio a falecer, desmobilizando-se as últimas facções da UNITA. Mas o problema das minas terrestres e da infra-estrutura destruída ainda levará tempo para ser resolvido.

Outro processo que representa uma renovação e desentrave da política africana resultou da guerra civil de mútuo extermínio em Ruanda e Burundi. Esse conflito foi mostrado pela mídia como uma decorrência do "tribalismo tradicional", mas, na realidade, resultou da deformação e reapropriação moderna de determinadas fraturas sociais da região. Os agricultores hútus formam quase $90 \%$ da população, enquanto os pastores tútsis, que chegaram mais tarde à região e constituíram uma aristocracia, representam 10\%. Durante a ocupação alemã e belga nessas duas colônias, os tútsis foram cooptados como elite no poder. Após a independência, o regime neocolonial de Ruanda passou a ser dominado pelos hútus e aliou-se incondicionalmente à França e ao Zaire. A hegemonia hútu, marcada por forte corrupção e exclusão estrutural dos adversários, começou a ser questionada no início da década. Refugiados tútsis, exilados há anos em Uganda, organizaram um pequeno exército (a Frente Patriótica Ruandesa - FPR), que penetrou no norte de Ruanda em outubro de 1990, sendo expulsos um mês depois pelo exército. Sentindo-se desgastado e ameaçado internamente, o governo massacrou tútsis em 1991 e 1992, como meio de fomentar uma divisão étnica, com vistas a permanecer no poder.

Apesar da assinatura dos Acordos de Arusha entre o governo e a oposição, a guerra civil foi reiniciada, com os rebeldes consolidando seu controle no norte e massacrando populações hútus. Frente ao impasse reinante no campo de batalha, no verão de 1993 foi estabelecido um governo de coalizão. Mas a paz estabelecida era frágil, e bastou que um hútu vencesse as eleições na vizinha Burundi para le- 
var os tútsis deste país a reagir. Em Ruanda, então, os extremistas hútus, ligados ao ex-presidente, aproveitaram-se da situação para atacar os tútsis e os hútus moderados. A crise agravou-se com a morte dos presidentes dos dois países, quando foi derrubado sobre Ruanda o avião que os transportava para uma reunião, destinada a resolver a crise. A partir daí, a guerra civil acirrou-se, e a FPR conquistou Kigali, a capital de Ruanda. Em 1994, teve início, então, um gigantesco massacre de hútus, que fez entre 500 mil e 800 mil mortos, e produziu um êxodo de 4 milhões de refugiados (numa população de 7,8 milhões), a maioria em direção aos países vizinhos, principalmente o fragilizado Zaire, que, junto com a França, era aliado do antigo governo. Os Estados Unidos imediatamente reconheceram o novo governo da FPR, que era também aliado de Uganda e Tanzânia.

O problema dos refugiados gerou tensões no Zaire, país que já enfrentava graves problemas internos, após malogradas tentativas de democratização. Em 1996, formou-se na região dos lagos, no leste, a Aliança das Forças Democráticas para a Libertação do Congo-Zaire, uma milícia composta principalmente por tútsis do Zaire. A Aliança era liderada por Laurent Kabila, um negociante de ouro e marfim, associado a meios empresariais norte-americanos, e que fora partidário de Lumumba no início dos anos 1960. Em menos de quatro meses, os rebeldes avançaram pelas províncias ricas do país até a capital, Kinshasa, sendo absorvidos por um vácuo, praticamente sem encontrar resistência. Obviamente, o Zaire de Mobutu era um gigante de pés de barro em desagregação, mas isso não era um fenômeno recente. Ele teria sobrevivido mais tempo, não fossem certos fatores externos.

Durante a Guerra Fria, a África fora uma área de influência predominantemente européia, com a França exercendo o papel de gendarme. Com a solução negociada dos conflitos regionais na passagem dos anos 1980 aos 1990, ironicamente os antigos Estados marxistas africanos, anteriormente aliados da URSS e inimigos da França, voltaram-se para os EUA, que abriram um espaço de influência direta no continente. Essa atitude revelava a profundidade das rivalidades regionais, entre os regi- 
mes marxistas e os pró-franceses. Apesar do fracasso na Somália, Washington passou a exercer influência direta sobre a Etiópia, Eritréia, Uganda, Angola e Moçambique, além da presença prévia no Quênia. Como resultado do conflito tútsis x hútus, essa projeção estendeu-se a Ruanda, Burundi e ao leste do Zaire, em detrimento da influência francesa.

\section{A Reafirmação: \\ a União Africana e o NEPAD}

As tendências de reafirmação da África no sistema mundial, as quais se esboçaram na segunda metade dos anos 1990, se aprofundaram na passagem do século. Apesar disso, os conflitos étnico-tribais e as guerras civis se mantiveram, atingindo, muitas vezes, níveis extremos de violência. Essa situação foi mais comum especialmente nos Estados do Golfo da Guiné e da África Ocidental. Na Libéria, os conflitos entre as populações do interior e as mais ocidentalizadas do litoral prosseguiram de forma intermitente, e na Serra Leoa, em 1999, o mesmo problema começou a se manifestar com intensidade. As populações do litoral, em grande parte descendentes de ex-escravos retornados das Américas, constituem a elite dirigente, discriminando os nativos. Alguns grupos políticos ou tribos, por outro lado, são financiados pelas grandes companhias de diamantes (particularmente as localizadas em Antuérpia) e outras pedras preciosas, com o objetivo de manter o controle das zonas de mineração, devido ao literal colapso do Estado e à desordem reinante.

Tudo isso agrava as tensões locais e propicia uma espécie de "privatização" da política e da violência armada, em meio a todo o tipo de tráfico, particularmente o de drogas, que tem crescido na África. A Nigéria, por sua vez, é conhecida por possuir uma poderosa máfia de narcotráfico, que já atua em todo o mundo. O fim do regime autoritário neste populoso país africano, por seu turno, tem propiciado ao país um maior protagonismo regional, como a participação em missões de paz da União Africana, embora persistam dificuldades sociais, apesar 
da imensa renda petrolífera. Outro país atingido por uma guerra civil foi a Costa do Marfim, onde os rebeldes apoderaram-se da metade norte do país em 2003, em sua luta contra o governo, tendo sido necessária uma intervenção francesa em apoio do mesmo.

Por outro lado, o processo de implantação de inúmeras democracias após a queda do Muro de Berlim, impulsionadas de fora para dentro através daquilo que Samuel Huntington denominou de "Terceira Onda" (a das democracias), parece estar retrocedendo. Antigos líderes de regimes autoritários de esquerda começaram a retornar ao poder. Com a guerra civil de 1997-1998, Denis Sassou Nguesso voltou ao poder na República Popular do Congo, com o apoio da empresa petrolífera francesa Elf-Aquitanie, em uma clara tentativa de rechaçar os interesses norte-americanos defendidos pelos regimes "democratizados". Mas o caso mais espetacular foi o fim da longa guerra civil em Angola, após a morte em combate do líder da UNITA, Jonas Savimbi, ocorrida em fevereiro de 2002. Savimbi controlava as minas de diamante do interior e devastava o país, enquanto o governo retirava seu rendimento do petróleo do litoral.

A África do Sul pós-Apartheid também tem promovido ativamente o multilateralismo no continente africano. A SADCC, Coordenação da Cooperação para o Desenvolvimento da África Austral, foi transformada em 1992 em Comunidade para o Desenvolvimento da África Austral -SADC -, com atribuições mais concretas e adesão de novos países, dinamizados pela entrada da África do Sul. ${ }^{1}$ Em setembro de 2001, a organização, que promove uma ativa integração na região, aprovou a criação de uma área de livre comércio entre os países-membros até 2008. A Organização da Unidade Africana, por sua vez, foi transformada em União Africana em julho de 2002. O apoio sul-africano e os recursos prometidos pelo líder líbio Kadafi (que já não está mais sob embargo internacional) foram decisivos para a ampliação dos objetivos da organização e a

\footnotetext{
${ }^{1}$ São membros África do Sul, Lesoto, Suazilândia, Botswana, Namíbia (estes países integram também a SACU, União Aduaneira da África Austral, fundada em 1910), Moçambique, Zimbábue, Malawi, Tanzânia, Maurício, Zâmbia, Angola, República Democrática do Congo e Madagascar.
} 
criação de condições para uma cooperação mais íntima entre os países do continente e para uma verdadeira integração. O presidente Mbeki, sucessor de Mandela, apoiou também a NEPAD, Nova Parceria Econômica para o Desenvolvimento Africano. Tudo isso contribuiu para que algumas eleições transcorressem com tranqüilidade, como a do Quênia e a de Madagascar, vencidas pela oposição, esta última apoiada pelos EUA.

Mas a África também passou a integrar os grandes temas e problemas mundiais. Epidemias devastadoras, como o vírus ébola e o HIVAIDS, não apenas causam danos presentes, como também comprometem o futuro, pois os infectados pelo último chegam a atingir 50\% em Botswana e 25\% na África do Sul. Ao lado de problemas no campo da saúde, existe uma dimensão social e econômica que se tornará mais aguda com o passar do tempo. Além disso, há guerras civis, fomes, destruição ambiental e narcotráfico, e o continente foi cenário de acontecimentos ligados à grande política mundial. Em julho de 1998, ocorreram atentados terroristas simultâneos nas embaixadas norteamericanas do Quênia e da Tanzânia, com um saldo de 250 mortos e 5000 feridos. O atentado teria sido articulado pela rede Al Qaeda, o que levou o então presidente norte-americano, Bill Clinton, a atacar com mísseis os campos de treinamento da mesma no Afeganistão.

Ao mesmo tempo, graças ao grande protagonismo diplomático da África do Sul, o continente passou a sediar algumas Conferências Internacionais da ONU. Em 2003, a União Africana tomou posição frontalmente contrária a qualquer ataque ao Iraque. Assim, a África, lentamente, vai se reafirmando e recuperando certo poder de barganha, como foi visto no caso do Iraque, quando os membros africanos do Conselho de Segurança da ONU foram cortejados pelos EUA e pela França. A liderança sul-africana e o retorno da Líbia ao cenário regional são elementos importantes, ao lado da afirmação das organizações multilaterais regionais e continentais.

A China também tem se feito presente no continente negro, tanto por razões econômicas (mercados e matérias-primas) quanto diplomáticas (combater a presença de Taiwan). Em novembro de 2006, foi reali- 
zada em Beijing a primeira Cúpula China-África, com a presença de mais de quarenta líderes africanos e o lançamento de uma espécie de "Plano Marshall" chinês para o continente, com investimentos em infra-estrutura e ajuda ao desenvolvimento. Isso tem sido acompanhado por um maior protagonismo francês. A histórica visita do ex-presidente da França Jacques Chirac à Argélia, em março de 2003, constitui um signo dessa tendência e sinaliza para a possibilidade desse importante país afro-árabe encerrar sua guerra civil e voltar a ter um maior protagonismo econômico e diplomático nos assuntos africanos. Por fim, o bloqueio da situação no Oriente Médio indica que a África poderá ter um papel mais relevante, na medida em que constitui uma retaguarda geopolítica dessa região. Ao mesmo tempo, o estabelecimento de laços com o Mercosul, com a Ásia e com a União Européia propiciará, a médio prazo, melhores condições para a África.

\section{Considerações Finais}

Nesse contexto, percebem-se algumas peculiaridades no convulsionado processo histórico africano e que precisam ser desmistificadas, tentando-se compreender os entraves e as potencialidades da inserção deste continente no sistema internacional do século XXI. Em primeiro lugar, é preciso descartar a visão segundo a qual a África é um continente voltado ao passado, em um contexto de conflitos insolúveis, e mesmo irracionais do ponto de vista ocidental. As sociedades africanas estão passando por um processo semelhante ao atravessado por outras regiões do mundo, qual seja, a construção dos modernos Estados nacionais.

Muito do que os europeus consideram absurdo na África constitui apenas a imagem contemporânea de processos semelhantes aos de seu próprio passado nem tão remoto. Quem se sente chocado pelas guerras de perfil étnico-tribal simplesmente esqueceu os sangrentos conflitos religiosos e proto-nacionais das monarquias dinásticas européias, a construção pela força dos Estados nacionais europeus, 
os quais esmagaram os regionalismos (alguns dos quais continuavam a fazê-lo ainda no final do século XX) ou a expansão dos colonizadores americanos, que exterminaram as comunidades indígenas. Esta semelhança, contudo, é ainda agravada pela herança do tráfico de escravos e pelo colonialismo imperialista, pois, segundo o líder nacionalista africano Amilcar Cabral, "o colonialismo pode ser designado como a paralisação ou a distorção, ou mesmo como o termo da história de um povo, e fator da aceleração do desenvolvimento histórico de outros povos".

O brevíssimo período que se seguiu à Segunda Guerra Mundial caracterizou-se, em primeiro lugar, por uma descolonização peculiar e tardia. A peculiaridade reside no fato da emancipação haver transcorrido largamente administrada pelas metrópoles européias, apesar da eclosão de alguns conflitos graves. Além disso, criaram-se mecanismos internacionais destinados a perpetuar essa situação, como as “ajudas" das ex-metrópoles.

Em meio a uma extrema fragilidade, iniciou-se o processo de construção do Estado-nação, como foi referido. Contudo, é necessário frisar que esse movimento histórico foi distorcido pela permanência das estruturas coloniais, através do neocolonialismo e, geralmente, da implantação de Estados inviáveis política e economicamente. Por outro lado, é forçoso reconhecer que se trata de um processo recente, de apenas algumas décadas, as quais equivalem à vida de uma pessoa de meia-idade. Ou seja, encontra-se ainda em suas fases iniciais. A retomada da História da África pelos africanos recém atravessa uma etapa comparável à Europa dos séculos XVI e XVII, ou às Américas do século XIX, mas em um mundo com os problemas ainda mais complexos do final do século XX e início do XXI.

\section{Referência}

VISENTINI, Paulo; RIBEIRO, Luiz Dario; PEREIRA, Analúcia Danilevicz. Breve história da África. Porto Alegre: Leitura XXI, 2007. 